\title{
Uzun Süreli Farklı Dozlarda Fosfor Uygulamalarının Mısır Bitkisinin Fosfor Kullanım Etkinliğinin Belirlenmesi
}

\author{
Mehmet IȘIK',* Feyzullah ÖZTÜRK' Șeyma KARADERE' İbrahim ORTAȘ \\ *Çukurova Üniversitesi, Ziraat Fakültesi, Toprak Bilimi ve Bitki Besleme Bölümü, 01330, Adana
}

\begin{abstract}
*Sorumlu yazar e-mail (Corresponding author e-mail): isikm@cu.edu.tr
Geliș tarihi (Received) : 24.02.2020

Kabul tarihi (Accepted): 02.10.2020

DOI: $10.21657 /$ topraksu.693254
\end{abstract}

\section{Öz}

Mısır (Zea Mays L.) bitkisi dünyada en çok üretilen tahıllardan birisidir. Mısır üretiminde en çok kullanılan gübrelerden biri olan fosfor (P) önümüzdeki 50-100 yıl içerisinde tükeneceği varsayılmakta ve bu da bitkisel üretimi kısıtlayacaktır. Bu sebeple çalıșmanın amacı; artan dozlarda P uygulamasının bitkinin P alımı ve P kullanım etkinliğini belirlemektir. Deneme 1998 yılında Çukurova Üniversitesi Araștırma ve Uygulama Çiftliğinde Arık toprak serisi üzerinde kurulmuș olup halen devam etmektedir. Söz konusu çakılı deneme düzenli olarak her ekim dönemi öncesi kontrol $\left(0 \mathrm{~kg} \mathrm{da}^{-1} \mathrm{P}_{2} \mathrm{O}_{5}\right)$, P5 (5 kg da-1 $\left.\mathrm{P}_{2} \mathrm{O}_{5}\right), \mathrm{P} 10$ ( $10 \mathrm{~kg} \mathrm{da}^{-1} \mathrm{P}_{2} \mathrm{O}_{5}$ ) ve P20 (20 kg da' $\mathrm{P}_{2} \mathrm{O}_{5}$ ) olacak șekilde uygulanmıș olup, bitkinin intiyaç duyduğu temel azot ve potasyum gübre gereksinimleri toprak analiz sonuçlarına göre belirlenmiștir. Deneme P2088 mısır çeșidi kullanılarak Mayıs 2017'de kurulmuș ve Eylül 2017'de de hasat edilmiștir. Hasat zamanı bitki farklı aksamları (kök, kök üstü aksam ve dane) kuru ağırlık verimleri alınmıștır. Kuru yakma metodu kullanılarak ICP-OES aleti ile bitki farklı aksamları P konsantrasyonları analiz edilmiștir. Elde edilen veriler ile Agronomik Etkinlik (AE), Fizyolojik Etkinlik (FE), Agro-Fizyolojik Etkinlik (AFE), Geri Kazanım Etkinliği (GKE) ve Gübre Kullanım Etkinliği (KE) hesaplanmıștır.

Araștırma bulgularına göre; artan dozlarda P uygulamalarının farkı bitki aksamları kuru madde verimini ve $P$ konsantrasyonunu arttırmaktadır. Ancak artan dozlarda P uygulamalarının AE, FE, GKE ve KE hesaplamalarına etkisine bakıldığında P10 uygulamasının istatistiksel olarak en iyi uygulama olduğu görülmektedir. Sonuç olarak araștırma bulguları $\mathrm{P} 10$ yani $10 \mathrm{~kg} \mathrm{da}^{-1} \mathrm{P}_{2} \mathrm{O}_{5}$ dozu uygulamasının Mısır bitkisinin gübrelemesinde optimum doz olduğunu göstermektedir.

Anahtar Kelimeler: Agronomik etkinlik, çakılı deneme, fosfor kullanım etkinliği, mısır

\section{Under Long Term Field Condition to Evaluate the Effects of Different Phosphorus Dosses on Agronomic Efficiency of Maize Plant}

\begin{abstract}
Maize (Zea Mays L.) plant is one of the most produced cereals around the world. Phosphorus (P), which is one of the most used fertilizers in maize production. $P$ is not a renewable resource and in next 50-100 years, it may be finish. Moreover, less $P$ fertilization may limit crop yield and production capacity. The purpose of study is to investigate the effects of different P dosses on P uptake and its usage efficiency upon maize plant under long term $\mathrm{P}$ fertilizer filed experiment. Long-term field experiment was established in 1998, since then regularly each year control (without fertilization), 5, 10 and $20 \mathrm{~kg}$ $\mathrm{P}_{2} \mathrm{O}_{5} \mathrm{da}^{-1} \mathrm{P}$ (as triple superphosphate) doses are applied as a basic fertilizers. P2088 maize genotype
\end{abstract}


was used as plant material. Maize seeds were sown in June 2017 and were harvested in October 2017. After harvest, yield, shoot and root dry weight were determined. P concentrations of each parts were determined by ICP-OES. Agronomic Efficiency (AE), Physiological Effciency (PE), Agrophysiological Effciency (APE), Apparent Recovery Effciency (ARE) and Utilization Effciency (EU) were calculated. According to the research findings; increasing doses of $P$ applications increase different plant parts dry matter yield and $\mathrm{P}$ concentration. However, it is seen that P10 application is statistically the best application on AE, FE, GKE and KE calculations. It was determined that under field condition application of $\mathrm{P} 10 \mathrm{~kg} \mathrm{da}{ }^{-1} \mathrm{P}_{2} \mathrm{O}_{5}$ dose was the optimum dose for maize production.

Keywords: Agronomic efficiency, long term field experiments, phosphorus utilization efficiency, maize

\section{Giriș}

Mısır (Zea mays L.) dünyada ve ülkemizde en çok üretilen bitkilerden biridir. Mısır karbonhidrat, protein, yağ, vitamin (A, E ve C vitaminleri) ve mineral içeriği ile insan sağlığı açısından önemli bir bitkisel üründür (Orhun, 2013). Mısır üretiminde en çok tüketilen gübrelerden biri de fosfor gübresidir.

Fosfor (P) yașayan canlılar (bitkiler ve hayvanlar) için gerekli bir besin elementtir. Dünyada ekilebilir alanların \%40'ında bitkisel üretimi sınırlandıran faktör fosfor noksanlığıdır (Balemi ve Negisho, 2012). Fosfor bitkilerde fotosentez, enerji, fosfolipit ve nükleik asit gibi pek çok metabolizmada görev almaktadır (Vance vd., 2003). Bitkiler fosforu suda çözünebilir fosfat iyonları olarak (özelliklede H2PO4- formunda) kökleri yardımı ile almaktadırlar (Roberts ve Johnston, 2015). Suda çözünmeyen fosfor formlarından bitkiler yararlanamaz (Rathinasabapathi vd., 2018). Yetersiz $P$ gübrelemesinde bitkisel üretim gerçekleșemeyeceği gibi așırı $P$ gübrelemesi durumunda ise ötrofikasyona neden olmaktadır (Frossard vd., 2016).

Yüksek $\mathrm{CaCO}_{3}$ ve $\mathrm{pH}$ içeriğine sahip topraklar Ca-P gibi bileșikler olușturarak P'un alınımı olumsuz etkilediği gibi (Marschner ve Rengel, 2007; Ortas ve Akpinar, 2011 ) düșük pH ya sahip topraklarda ise Fe-P gibi birleșikler olușturarak P'un alınımı olumsuz etkilenir (Yli-Halla, 2016). Dolayısıyla ülke ve bölge topraklarımızın çoğu yüksek $\mathrm{CaCO}_{3}$ ve $\mathrm{pH}$ içeriğine sahip olduğu için P tarım alanlarına çok uygulansa da ancak küçük bir kısmından bitki yararlanabilmektedir. Yenilenebilir bir kaynak olmayan P'un rezervi apatit kayasıdır. Apatit kayası önümüzdeki 50-100 yıl içerisinde tükeneceği varsayılmaktadır (Schnug ve Haneklaus, 2016).

Apatit kayasının tükenebilir bir kaynak olması P kullanım etkinliğinin önemini her geçen gün arttırmaktadır (Veneklaas vd., 2012). P kullanım etkinliği optimum koșullarda \%25'e kadar arttırılabilir (Shenoy ve Kalagudi, 2005). P kullanım etkinliği pek çok yolla tanımlanmaktadır (Fageria, 1992). Ancak en yaygın tanımlama ise; biyokütle veya verim miktarına karșıllık kaldırılan besin elementi miktarıdır (Veneklaas vd., 2012). Kullanım etkinlikleri hesaplamalarında genel olarak en büyük hedef minimum gübre uygulamasına maksimum verim elde edilmesidir. P kullanım etkinliği yeni bir konu değildir. Ancak henüz tam olarak anlașılmıș bir konu olmamakla birlikte mısırda kullanım etkinliği hesaplamaları ile ilgili çalıșmalarda sınırlıdır.

Bu sebeple ülkemiz ve bölgemizde en çok üretilen bitkisel ürünlerden biri olan mısırın fosfor kullanım etkinliğini hesaplamak ve en uygun $P$ dozunu uzun süreli deneme koșullarında belirlemek büyük öneme sahiptir. Bu sebeple çalıșmanın amacl; artan dozlarda P uygulamasının bitkinin P alımı ve P kullanım etkinliğini belirlemektir. Çalıșmada test edilecek hipotez ise; artan dozlarda $\mathrm{P}$ uygulaması fosforlu gübre kullanım etkinliğini arttıır.

\section{MATERYAL VE YÖNTEM}

Deneme 1998 yllında Çukurova Üniversitesi Araștırma ve Uygulama Çiftliğinde Arık (Vertisol Ordosundan, Haploxerert büyük grubu ve Typic Haploxerert alt grubunda yer alan) serisi toprak (USA, 1975) üzerinde kurulmuș olup halen devam etmektedir. Arık toprak serisi \%0-1 eğime sahip oldukça derin profilli yașı alüviyal taban arazilerde yer alan A-C horizonlarından olușmaktadır. Profil rengi koyu kahverengi ve kahverengidir. Tüm profil kireçli ve killi olup kireç yıkanması çok az görülmektedir (Gülez ve Șenol, 2002). Arık serisi toprakların bazı fiziksel ve kimyasal özellikleri Çizelge l'de gösterilmiștir. Söz konusu çakllı deneme düzenli olarak her ekim dönemi öncesi kontrol 10 $\left.\mathrm{kg} \cdot \mathrm{da}^{-1} \mathrm{P}_{2} \mathrm{O}_{5}\right), \mathrm{P} 5\left(5 \mathrm{~kg} \cdot \mathrm{da} \mathrm{a}^{-1} \mathrm{P}_{2} \mathrm{O}_{5}\right), \mathrm{P} 10\left(10 \mathrm{~kg} \cdot \mathrm{da}^{-1}\right.$ 
Çizelge 1. Arık serisi toprakları bazı fiziksel ve kimyasal özellikleri (Cenkseven vd., 2019)

Table 1. Some physical and chemical properties of Arık series soils (Cenkseven et al., 2019)

\begin{tabular}{|c|c|c|c|c|c|c|c|}
\hline \multirow{2}{*}{$\begin{array}{c}\mathrm{pH} \\
(1: 2.5)\end{array}$} & \multirow{2}{*}{$\begin{array}{c}\text { Toplam N } \\
(\%)\end{array}$} & \multirow{2}{*}{$\begin{array}{c}\text { C Org. } \\
(\%)\end{array}$} & \multirow{2}{*}{$\begin{array}{c}\mathrm{P} \\
\left(\mathrm{mg} \mathrm{kg}^{-1}\right)\end{array}$} & \multicolumn{3}{|c|}{ Tekstür dağılımı (\%) } & \multirow[t]{2}{*}{ Tekstür sınıfı } \\
\hline & & & & Kum & Silt & Kil & \\
\hline 8.09 & 0.12 & 1.4 & 11.43 & 19.6 & 30.8 & 49.6 & C \\
\hline
\end{tabular}

$\left.\mathrm{P}_{2} \mathrm{O}_{5}\right)$ ve P20 (20 kg.da-1 $\left.\mathrm{P}_{2} \mathrm{O}_{5}\right)$ olacak șekilde uygulanmıș olup, bitkinin intiyaç duyduğu temel azot ve potasyum gübre gereksinimleri toprak analiz sonuçlarına göre belirlenmiștir. Deneme P2088 çeșidi mısır kullanılarak Mayıs 2017'de kurulmuș ve Eylül 2017'de de hasat edilmiștir.

Hasat zamanı bitki farklı aksamları (kök, kök üstü aksam ve dane) kuru ağırlık verimleri alınmıștır. Ayrıca kuru yakma metodu kullanılarak ICP-OES aleti ile bitki farklı aksamları P konsantrasyonları analiz edilmiștir (Kacar ve İnal, 2008). Elde edilen veriler ile Fageria ve Filho (2007) ya göre Agronomik Etkinlik (AE), Fizyolojik Etkinlik (FE), Agro-Fizyolojik Etkinlik (AFE), Geri Kazanım Etkinliği (GKE) ve Gübre Kullanım Etkinliği (KE) hesaplanmıștır (Çizelge 2).
Araștırma bulgularına JMP 8 istatistik programı kullanılarak ANOVA analizi ve LSD testi gerçekleștirilmiștir.

\section{BULGULAR VE TARTIȘMA}

\section{Farklı bitki aksamları kuru madde verimi}

Artan dozlarda P uygulamalarının mısır aksamları (kök, kök üstü ve dane) kuru madde verimi incelendiğinde (Çizelge 3) istatistiksel olarak dikkate değer bir fark vardır. Tüm aksamlarda, istatistiksel olarak P20 uygulaması kontrol uygulamasına göre en iyi uygulama olurken onu sırası ile P10 ve P5 uygulamaları izlemektedir. Artan dozlarda P uygulaması bitki gelișimini arttırdığına dair pek çok çalıșma yapılımıștır.

Çizelge 2. P kullanım etkinliklerinin formülleri (Fageria ve Filho, 2007)

Table 2. Formula of P use efficiency (Fageria and Filho, 2007)

Besin Elementi Etkinliği

Agronomik Etkinlik (AE) (FE)

Agro-Fizyolojik Etkinlik (AFE)

Geri Kazanım Etkinliği (GKE)
Formüller ve Tanımları

Agronomik etkinlik element alımına karșılık ekonomik üretim olarak tanımlanır. Hesaplanmasında AE (kg dane $\left.\mathrm{kg}^{-1} \mathrm{P}\right)=\mathrm{GF}-\mathrm{GU} / \mathrm{NA}$ formülü kullanılır ve GF gübre uygulanmıș parsellerin dane verimi (kg), GU gübre uygulanmamıș parsellerin dane verimi ve NA uygulanan P miktarı (kg) olarak tanımlanır.

Fizyolojik etkinlik alınan elemente karșılık biyolojik verim olarak tanımlanır. Hesaplanmasında FE (kg biokütle $\left.\mathrm{kg}^{-1} \mathrm{P}\right)=$ BYF-BYU/NF-NU formülü kullanılır BYF gübre uygulanan parsellerin biyolojik (tane ve anız ağırlığı) verimliliği (kg), BYU gübre uygulanan parsellerin biyolojik verimliliği (kg), NF gübre uygulanan parsellerdeki bitkilerin ( tane ve anız ) kaldırdığı P miktarı (kg) ve NU ise gübre uygulanmayan parsellerdeki bitkilerin (tane ve anız) kaldırdığı P miktarı (kg) olarak tanımlanır.

Agro-fizyolojik etkinlik element alımına karșılık ekonomik üretim olarak tanımlanmaktadır. Hesaplamasında AFE (kg dane $\left.\mathrm{kg}^{-1} \mathrm{P}\right)=\mathrm{GF-GU/NUF-}$ NUU formülü kullanılır ve GF gübre uygulanan parsellerde tane verimi, GU gübre uygulanmayan parsellerde tane verimi (kg), NUF gübre uygulanan parsellerdeki bitkinin (tane ve anız) kaldırdığı P miktarı (kg) ve NUU gübre uygulanmayan parsellerdeki bitkinin (tane ve anız) kaldırdığı P miktarı (kg) olarak tanımlanır.

Geri kazanım etkinliği uygulanan gübreye karșılık kaldırılan besin elementi miktarı olarak tanımlanır. Hesaplanması ARE (\%)=(NF-NU/NA)* 100, NF gübre uygulanan parsellerdeki bitkilerin (tane ve anız) kaldırdığı P miktarı

(kg), NU gübre uygulanmayan parsellerdeki bitkilerin (tane ve anız) kaldırdığı P miktarı (kg) ve NA parsellere uygulanan P gübrelemesi (kg) olarak tanımlanır. 
Aydın vd. (2005)nin yapmıș olduğu çalıșmada artan dozlarda P uygulamasına bağlı olarak bitki kuru madde verimininde arttığı görülmektedir. Ayub vd. (2002) yapmıș olduğu çalıșmada mısır bitkisine artan dozlarda $N$ ve $\mathrm{P}$ uygulamaları gerçekleștirmiștir. Söz konusu çalıșmanın araștırma bulguları genel olarak artan dozlarda NP uygulamasına bağlı olarak bitki verimininde arttığını göstermekte olup çalıșmamızı destekler niteliktedir.

Farklı bitki aksamlarının $\mathbf{P}$ içerikleri ve kaldırılan P miktarları

Artan dozlarda $P$ uygulamalarının farklı bitki aksamları P içeriğine etkisi incelendiğinde (Çizelge 4) kök üstü aksam hariç istatistiksel olarak uygulamalar arasında önemli fark olmadığı görülmektedir. Kök üstü aksam olarak ise en iyi uygulamalar P20 ve P10 uygulamalarıdır. Ayrıca artan dozlarda P uygulamasına bağlı olarak farklı bitki aksamlarının ortalama P içerikleri genel olarak arttığı görülmektedir.

Artan besin elementi uygulamasına bağlı olarak bitki dokularında besin elementi birikimi beklenen bir durumdur. Sanginga (1992) nın yapmıș olduğu çalıșma araștırma bulgularımızı destekler niteliktedir. Bitki kuru madde verimi ve dokulardaki P konsantrasyonuna bağlı olarak bitki dokuları kaldırdığı $P$ miktarıda artması beklenmektedir. Artan dozlarda P uygulamasının bitki aksamlarınca kaldırılan $P$ miktarına etkisine bakıldığında istatistiksel olarak önemli farklar vardır (Çizelge 5). Kök üstü aksam, kök, dane ve toplam biyomas kaldırılan P miktarı incelendiğinde P20 uygulaması istatistiksel olarak en iyi uygulamadır. Mohammad vd. (1998) yapmıș olduğu çalıșmada artan dozlarda P uygulaması bağlı olarak bitkinin kaldırdığı P miktarıda artıș gösterdiğini rapor etmișlerdir.

Çizelge 3. Artan dozlarda P uygulamalarının kök, kök üstü aksam, dane ve toplam biyomas kuru madde verimlerine etkisi Table 3. The effect of increasing doses $P$ applications on root, shoot, grain and total biomass dry matter yields

\begin{tabular}{|c|c|c|c|c|}
\hline \multirow{2}{*}{ Uygulamalar } & Kök Kuru Ağırlığı & Kök Üstü Kuru Ağırlığı & Dane Kuru Ağırlığı & Toplam Biyomas Kuru Ağırlığı \\
\hline & \multicolumn{4}{|c|}{$\left(k g d a^{-1}\right)$} \\
\hline PO & $158 \pm 20 c$ & $621 \pm 42 c$ & $635 \pm 56 \mathrm{~b}$ & $1414 \pm 35 c$ \\
\hline P5 & $186 \pm 22 b c$ & $666 \pm 97 b c$ & $765 \pm 100 b$ & $1617 \pm 28 c$ \\
\hline $\mathrm{P} 10$ & $207 \pm 19 a b$ & $782 \pm 61 a b$ & $952 \pm 88 a$ & $1941 \pm 102 b$ \\
\hline \multirow[t]{2}{*}{ P20 } & $229 \pm 5 a$ & $893 \pm 108 a$ & $1090 \pm 95 a$ & $2211 \pm 209 a$ \\
\hline & $p<0.05$ & $p<0.01$ & $p<0.01$ & $p<0.01$ \\
\hline
\end{tabular}

Çizelge 4. Farklı bitki aksamları (\%) P konsantrasyonları

Table 4. Different plant parts (\%) P concentrations

\begin{tabular}{cccc}
\hline Uygulamalar & Kök & Kök Üstü & Dane \\
\cline { 2 - 4 } & & $\mathrm{P}(\%)$ & $0.22 \pm 0.02$ \\
\hline P0 & $0.03 \pm 0.01$ & $0.04 \pm 0.01 \mathrm{~b}$ & $0.24 \pm 0.01$ \\
P5 & $0.04 \pm 0.01$ & $0.04 \pm 0.01 \mathrm{ab}$ & $0.21 \pm 0.04$ \\
P10 & $0.04 \pm 0.01$ & $0.07 \pm 0.02 \mathrm{a}$ & $0.22 \pm 0.02$ \\
P20 & $0.05 \pm 0.01$ & $0.07 \pm 0.02 \mathrm{a}$ & $\mathrm{p}>0.05$ \\
\hline
\end{tabular}

Çizelge 5. Farklı bitki aksamları tarafından kaldırılan P miktarları

Table 5. P uptake of different plant parts

\begin{tabular}{ccccc}
\hline \multirow{2}{*}{ Uygulamalar } & Kök & Kök Üstü & Dane & Toplam Biyomas \\
\cline { 2 - 5 } & \multicolumn{5}{c}{$\left(\mathrm{P} \mathrm{kg} \mathrm{da}^{-1}\right)$} \\
P0 & $0.05 \pm 0.02$ & $0.27 \pm 0.11 \mathrm{~b}$ & $1.4 \pm 0.1 \mathrm{~b}$ & $1.7 \pm 0.1 \mathrm{c}$ \\
P5 & $0.06 \pm 0.01$ & $0.24 \pm 0.30 \mathrm{~b}$ & $1.9 \pm 0.2 \mathrm{ab}$ & $2.2 \pm 0.2 \mathrm{bc}$ \\
P10 & $0.09 \pm 0.03$ & $0.57 \pm 0.23 \mathrm{a}$ & $2.0 \pm 0.5 \mathrm{ab}$ & $2.7 \pm 0.3 \mathrm{ab}$ \\
P20 & $0.11 \pm 0.03$ & $0.67 \pm 0.26 \mathrm{a}$ & $2.4 \pm 0.3 \mathrm{a}$ & $3.2 \pm 0.6 \mathrm{a}$ \\
\hline & $\mathrm{p}>0.05$ & $\mathrm{p}<0.01$ & $\mathrm{p}<0.05$ & $\mathrm{p}<0.01$ \\
\hline
\end{tabular}




\section{Farklı dozlarda $\mathbf{P}$ uygulamalarının kullanım etkinlikleri üzerine etkisi}

Fosfor kullanım etkinlikleri hesaplandığında (AE, FE, KE ve GKE) farklı dozlarda P uygulamaları arasında istatitiksel olarak önemli farklar vardır (Çizelge 6). AE hesaplaması incelendiğinde (Çizelge 6) bir $\mathrm{kg} P$ gübrelemesine $34 \mathrm{~kg}$ verim ile P10 uygulaması en iyi uygulamadır. P20 uygulamasında ise $A E^{\prime}$ nin düștüğü görülmektedir. Benzer șekilde García ve Salvagiotti (2010) yapmıș olduğu çalıșmada soya fasülyesine artan dozlarda $P\left(0,10,20\right.$ ve $\left.40 \mathrm{~kg} \mathrm{ha}^{-1}\right)$ uygulamıș olup $A E$ hesaplanmıștır. Söz konusu çalıșmada AE bir noktaya kadar $(10 \mathrm{~kg} \mathrm{ha-1})$ artarken sonrasında azalıșa geçmiștir.

FE ve GKE hesaplamaları incelendiğinde ise istatistiksel olarak uygulamalar arasında önemli farkların olduğu görülürken AFE hesaplamasında istatistiksel olarak bir fark yoktur. Istatistiksel olarak P5 ve P20 dozlarına kıyasla en iyi FE ve GKE P10 dozudur. Ortalama AFE hesaplaması olarak ise P5 ve P20 uygulamalarına kıyasla en iyi uygulama P10 uygulamasıdır. Araștırma bulgularımızın aksine Hussein (2009) mısır da gerçekleștirmiș olduğu denemede tek üretim sezonu boyunca farklı dozlarda $\left(0,30,60\right.$ ve $\left.90 \mathrm{~kg} \mathrm{P} \mathrm{ha}^{-1}\right) \mathrm{P}$ uygulanmıș olup artan dozlarda P uygulamasına bağı olarak GKE etkinliği azalma eğilimi göstermiștir.

FE kaldırılan P miktarına bağı olarak elde edilen biyolojik verimdir (Snyder, 2009). FE olarak P10 (744 $\mathrm{kg} \mathrm{kg}^{-1}$ ) uygulaması P5 ve P20 uygulamasına göre en iyi uygulamadır. Düșük FE düșük verime neden olmaktadır (Dobermann, 2007). AFE, KE ve GKE hesaplamalarında yine benzer șekilde P10 uygulaması P5 ve P20 uygulamasına göre en iyi uygulamadır (Çizelge 6). Uzun yıllar uygulanan $P$ gübrelme koșulları altında dekara $20 \mathrm{~kg}$ $\mathrm{P}_{2} \mathrm{O}_{5}$ uygulamasının bitki gelișimi en yüksek gübre dönüșüm etkisine sahip olduğu görülmektedir. Araștırma bulgularımıza benzer șekilde Fageria ve
Filho (2007) de yaptıkları çalıșmada farklı dozlarda P uygulaması altında pirinç P kullanım etkinliklerinin (AFE, GKE ve KE) bir noktaya kadar artarken sonrasında düșüș gösterdiğini belirlemișlerdir.

\section{SONUÇLAR}

Sonuç olarak, araștırma bulgularımız gösteriyor ki topraklara artan dozlarda P uygulaması mısır bitkisinin büyümesini arttırmıștır. Aynı zamanda Agronomik Etkinlik, Fizyolojik Etkinlik, AgroFizyolojik Etkinlik, Geri Kazanım Etkinliği ve Gübre Kullanım Etkinliği hesaplanmıș ve Cukurova bölgesi koșullarında mısır yetiștiriciliği için en iyi $\mathrm{P}$ dozu uygulaması $10 \mathrm{~kg} \mathrm{P}_{2} \mathrm{O}_{5} \mathrm{da}^{-1}$ olduğu belirlenmiștir.

\section{KAYNAKLAR}

Aydın A, Kant C, Ataoğlu N (2005). Erzurum ve Rize yöresi toprak örneklerine uygulanan farklı dozlardaki bor ve fosforun mısır (Zea mays)'ın kuru madde miktarı ve mineral içeriğine etkisi. Atatürk Üniversitesi Ziraat Fakültesi Dergisi 36: 125-129.

Ayub M, Nadeem M, Sharar M, Mahmood N (2002). Response of maize (Zea mays L.) fodder to different levels of nitrogen and phosphorus. Asian Journal of Plant Sciences 1 : 352-354.

Balemi T, Negisho K (2012). Management of soil phosphorus and plant adaptation mechanisms to phosphorus stress for sustainable crop production: a review. Journal of soil science and plant nutrition 12: 547-562.

Cenkseven Ș., Koçak B., Kizildağ N., Aka Sagliker H., Darici C., (2019). Negative priming effects of emamectin benzoate on soil microbial activity", Journal of environmental protection and ecology, vol.20, pp. $1140-1148$.

Dobermann A, (2007). Nutrient use efficiencymeasurement and management. Fertilizer best management practices 1 .

Fageria N, Filho M B 2007. Dry-matter and grain yield, nutrient uptake, and phosphorus use-efficiency of lowland rice as influenced by phosphorus fertilization. Communications in soil science and plant analysis 38: 1289-1297.

Fageria N K (1992). Maximizing crop yieldsCRC Press. 2005. Fertilización azufrada en maíz en la pampa ondulada. Congreso Nacional de Maíz. 8. 200511 16-18, 16 al 18 Noviembre 2005. Rosario, Santa Fe. AR.

Çizelge 6. P kullanım etkinlikleri hesaplamaları

Table 6. Calculation of $P$ use efficincy

\begin{tabular}{|c|c|c|c|c|c|}
\hline \multirow{2}{*}{ Uygulamalar } & $\mathrm{AE}$ & $\mathrm{FE}$ & AFE & $\mathrm{KE}$ & GKE \\
\hline & $\left(\mathrm{kg}\right.$ dane $\left.\mathrm{kg}^{-1} \mathrm{P}\right)$ & $\left(\mathrm{kg}\right.$ biokütle $\left.\mathrm{kg}^{-1} \mathrm{P}\right)$ & ( $\mathrm{kg}$ dane $\mathrm{kg}^{-1} \mathrm{P}$ ) & $\left(\mathrm{kg}\right.$ biokütle $\left.\mathrm{kg}^{-1} \mathrm{P}\right)$ & $(\%)$ \\
\hline P5 & $18 \pm 8 b$ & $421 \pm 35 b$ & $264 \pm 31$ & $39 \pm 3 b$ & $8 \pm 1 b$ \\
\hline P10 & $32 \pm 3 a$ & $744 \pm 111 a$ & $377 \pm 76$ & $59 \pm 9 a$ & $12 \pm 1 a$ \\
\hline \multirow[t]{2}{*}{ P20 } & $19 \pm 2 b$ & $674 \pm 74 a$ & $303 \pm 56$ & $50 \pm 0 a$ & $6 \pm 0 c$ \\
\hline & $p<0.05$ & $p<0.05$ & $p>0.05$ & $p<0.05$ & $p<0.05$ \\
\hline
\end{tabular}


Frossard E E, Bünemann K, Gunst L, Oberson A, Schärer M, Tamburini $F$ (2016). Fate of Fertilizer $P$ in Soils-The Organic Pathway. Phosphorus in Agriculture: 100\% Zero. Springer. p. 41-61.

García F, Salvagiotti F, (2010). Fertilizer best management practices in Argentina with emphasis on cropping systems. Boas practicas para uso eficiente de fertilizantes 1: 111-142.

Gülez, M. and S. Șenol. 2002. Çukurova Üniversitesi Ziraat Fakültesi Toprak Bölümü Deneme Alanının Detaylı Toprak Etüd ve Haritalaması. ÇÜ ZF Dergisi 17: 103-110.

Hussein A, (2009). Phosphorus use efficiency by two varieties of corn at different phosphorus fertilizer application rates. Res. J. Appl. Sci 4: 85-93.

Kacar B, İnal A, (2008). Plant analysis (In Turkish). Nobel Yayın No: 1241

Marschner P, Rengel Z, (2007). Nutrient cycling in terrestrial ecosystemsSpringer Science \& Business Media.

Mohammad M, Shibli R, Ajlouni M, Nimri L, (1998). Tomato root and shoot responses to salt stress under different levels of phosphorus nutrition. Journal of plant nutrition 21 : 1667-1680.

Orhun G E, (2013). Maize for life. International Journal of Food Science and Nutrition Engineering 3: 13-16.

Ortas I, Akpinar Ç, (2011). Response of maize genotypes to several mycorrhizal inoculums in terms of plant growth, nutrient uptake and spore production. Journal of plant nutrition 34: 970-987.

Rathinasabapathi B, Liu X, Cao Y, Ma L O, (2018). "Phosphate-solubilizing Pseudomonads for improving crop plant nutrition and agricultural productivity." Crop Improvement Through Microbial Biotechnology. Elsevier, 363-372.

Roberts T L, Johnston A E, (2015). Phosphorus use efficiency and management in agriculture. Resources, Conservation and Recycling 105: 275-281. doi:https://doi. org/10.1016/j.resconrec.2015.09.013.
Sanginga N, (1992). Early growth and N 2-fixation of leucaena and gliricidia at different levels of phosphorus application. Fertilizer Research 31: 165-173.

Schnug E, Haneklaus S H, (2016). The enigma of fertilizer phosphorus utilization. Phosphorus in Agriculture: 100\% Zero. Springer. p. 7-26.

Shenoy V V, Kalagudi G M, (2005). Enhancing plant phosphorus use efficiency for sustainable cropping. Biotechnology Advances 23: 501-513. doi:https://doi. org/10.1016/j.biotechadv.2005.01.004.

Snyder C S, 12009. Nutrient Use Efficiency: Global Challenges, Trends, and the future. Proceedings of the Symposium" Nutrient Use Efficiency" presented by the International Plant Nutrition Institute (IPNI) at the XVIII Latin American Congress of Soil Science. San Jose, Costa Rica, November.

USA, 1975. Soil Survey Staff. Soil Taxonomy: a basic system of soil classification for making and interpreting soil surveys. Agriculture Handbook noU. S. Government Printing OfficeWashington DC

Vance C P, Unde-Stone C, Allan D L, (2003). Phosphorus acquisition and use: critical adaptations by plants for securing a nonrenewable resource. New phytologist 157: 423-447.

Veneklaas E J, H. Lambers J, Bragg P M, Finnegan C E, Lovelock W C., Plaxton, ... Raven J A, (2012). Opportunities for improving phosphorus-use efficiency in crop plants. New Phytologist 195: 306-320.

Yli-Halla $M,(2016)$. Fate of fertilizer $P$ in soils: inorganic pathway. Phosphorus in Agriculture: 100\% Zero. Springer. p. 27-40. 